\title{
Data report: magnetic properties of basalts from Shatsky Rise ${ }^{1}$
}

\author{
Claire Carvallo ${ }^{2}$ and Pierre Camps ${ }^{3}$
}

\section{Chapter contents}

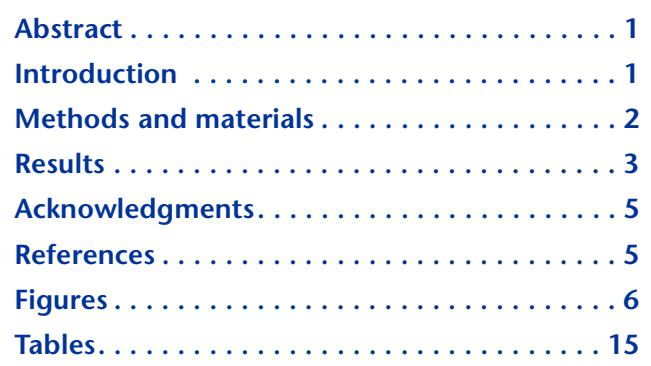

${ }^{1}$ Carvallo, C., and Camps, P., 2013. Data report: magnetic properties of basalts from Shatsky Rise. In Sager, W.W., Sano, T., Geldmacher, J., and the Expedition 324 Scientists, Proc. IODP, 324: Tokyo (Integrated Ocean Drilling Program Management International, Inc.).

doi:10.2204/iodp.proc.324.201.2013

${ }^{2}$ Institut de Minéralogie et de Physique de Milieux Condensés, Université Pierre et Marie Curie, Paris, France. carvallo@impmc.upmc.fr

${ }^{3}$ Geosciences Montpellier, CRNS and Université Montpellier 2, Montpellier, France.

\section{Abstract}

A detailed study of magnetic properties was carried out on $\sim 60$ samples from three holes cored during Integrated Ocean Drilling Program Expedition 324, Shatsky Rise. The measurements include scanning electron microscopy (SEM), hysteresis, and first-order reversal curve (FORC) diagrams, as well as measurements of susceptibility at high and low temperatures and variation of saturation isothermal magnetization at low temperature. SEM measurements show the presence of a complex mixture of Fe-Ti oxides with various Ti content $x$, which is confirmed by the measurements of susceptibility variation with temperature and low-temperature measurements. According to FORC diagrams, the magnetization is carried by single-domain to pseudosingle-domain grains.

\section{Introduction}

Shatsky Rise was cored during Integrated Ocean Drilling Program Expedition 324 because it is a unique oceanic plateau, formed mainly during the Late Jurassic and Early Cretaceous at a rapidly spreading triple junction, with characteristics that could be attributed to either of two competing hypotheses for ocean plateau formation: plume head or plate boundary processes (Sager, 2005). Shatsky Rise is also a monster volcanic construct whose formation style is poorly understood. The goal of Expedition 324 was to core the igneous rocks of Shatsky Rise and the overlying sediments to examine the age, physical volcanology, geochemistry, and tectonic evolution of the rise as well as the sedimentation history.

Thermal and alternating field (AF) demagnetizations were carried out by the shipboard paleomagnetists on discrete samples in order to give an estimate of the inclination of the recorded geomagnetic field. According to the wide variation of coercive field and unblocking temperature spectra, it is clear that the nature and size of the magnetization carriers are very diverse, even within one hole or one lava flow (see the "Expedition 324 summary" chapter [Expedition 324 Scientists, 2010a]).

Approximately 60 samples from Holes U1347A, U1349A, and U1350A were collected for Thellier-Thellier paleointensity experiments. In order to select samples that would have the best chances for successful paleointensity determinations, the samples were chosen from lava flows for which the shipboard-based AF demagnetization spectra (magnetization versus AF demagnetizing 
field) showed an initial plateau at low demagnetizing field, which is usually characteristic of single-domain behavior. Also, the bulk susceptibility variations, measured after each heating step in the thermal demagnetizations, were selected to be as small as possible in order to avoid samples that would alter during the paleointensity experiments. We selected 14 samples from Hole U1347A, all from the same basaltic massive flow (stratigraphic Unit XV in the "Site U1347" chapter [Expedition 324 Scientists, 2010b); 22 samples from Hole U1349A, from 5 different subunits of the same stratigraphic unit; and 24 samples from Hole U1350A, 2 from stratigraphic Subunit IIc (stack of thin inflation units) and 22 from Unit IV (stack of $\sim 0.1-0.5 \mathrm{~m}$ thick plagioclase-phyric pillow lavas) (see the "Site U1350" chapter [Expedition 324 Scientists, 2010c). We tried to take two or three samples per pillow lava unit or thin inflation unit whenever possible. No samples were collected from Hole U1346A because the AF demagnetization behavior described above could not be identified in any lava flow in this hole.

In order to characterize the carriers of the magnetization, several rock magnetic measurements were carried out. The paleointensity experiments are described elsewhere (Carvallo et al., in press). In short, 9 samples out of 60, all from Hole U1349A, gave reliable paleointensity estimates. Samples from Hole U1347A failed because of concave-curved Arai plots, and samples from Hole U1350A failed because of important alteration that took place during the repeated heating, combined with very low Curie temperatures. The goal of this data report is to document the magnetic measurements done on these samples, including scanning electron microscope (SEM) observations, and it contains all measured data; a subset of these data is included in Carvallo et al. (in press).

\section{Methods and materials}

\section{Scanning electron microscope observations}

SEM observations are useful for determining the size and morphology of the iron oxides as well as identifying the chemical elements present in the sample using X-ray diffraction. The observations were performed at the Institut de Minéralogie et de Physique des Milieux Condensés on selected samples prepared as rock powder mounted on carbon stubs using a SEM/FRG ZEISS Ultra 55 scanning electron microscope, and the concentrations of heavy metals were determined with the help of a Noran System 7 energy dispersive spectrometer (EDS) detector. The spatial resolution is $\sim 1 \mu \mathrm{m}$.

\section{Hysteresis and first-order reversal curve diagram measurements}

First-order reversal curve (FORC) diagrams are an extension of hysteresis measurements that allow qualitative characterization of the magnetic domain structure and magnetostatic interactions even for materials containing a mixed grain-size assemblage (Pike et al., 1999; Roberts et al., 2000). When measuring a FORC diagram, the inside of the hysteresis loop is explored, which gives access to the distribution of microcoercivity rather than bulk coercivity, as when measuring simple hysteresis loops. FORC diagrams were measured at the Laboratoire des Sciences du Climat et de l'Environnement (LSCE), Gifsur-Yvette, using an alternating gradient magnetometer. One hundred FORCs were measured with an averaging time of $0.1 \mathrm{~s}$. The FORC diagrams were drawn using the method described in Pike et al. (1999). At least one sample per lava flow or unit was measured.

In simple cases, as is the case here, one way of quantifying FORC diagrams is by measuring the coercivity field that corresponds to the maximum of the FORC distribution and the full-width at half-maximum (FWHM) of the distribution profile parallel to the coercive field $H_{\mathrm{c}}=0 \mathrm{mT}$ axis that goes through the maximum of the distribution. This gives a measurement of the interaction field.

\section{Susceptibility versus temperature}

Low-field susceptibility versus temperature curves $(k$ $T$ curves) were measured in order to test the stability of the Fe-Ti oxides upon heating and to determine the Curie temperature. Measurements were performed at low and high temperatures with the CS-L cryostat apparatus and the CS-3 furnace under argon atmosphere coupled to the KLY 3 Kappabridge (Agico, Czech Republic) at the University of Montpellier. For this experiment, bulk rock samples were reduced to powder in an agate mortar and sieved to obtain $0.4-0.8 \mathrm{~mm}$ size fractions. At least one sample per flow was heated first from liquid nitrogen temperature $(78 \mathrm{~K}$ ) to $900 \mathrm{~K}$ and cooled to room temperature. In some cases, the low-temperature measurements were repeated by heating again from $78 \mathrm{~K}$ to room temperature. Raw susceptibility data were corrected for the empty sample holder and normalized to the maximum susceptibility. At least one sample per lava flow was measured.

\section{Low-temperature measurements}

Low-temperature magnetization curves were measured with a magnetic properties measurement sys- 
tem from Quantum Design at the Institut de Physique du Globe de Paris. A $2.5 \mathrm{~T}$ magnetic field was first applied in order for the samples to acquire a saturation isothermal remanent magnetization (SIRM), the samples were cooled to $10 \mathrm{~K}$ in zero-field, and their magnetization was measured during the cooling run. Subsequently, the samples were given another SIRM in a $2.5 \mathrm{~T}$ field at $10 \mathrm{~K}$ and then warmed in zero-field to $300 \mathrm{~K}$, and the magnetization was measured during the heating run. At least one sample per lava flow was measured.

\section{Results}

\section{Scanning electron microscope observations}

\section{Hole U1347A}

Four samples were analyzed. The Fe-Ti oxides show various morphologies even within one sample. The presence of skeletal grains in some samples (e.g., Sample 324-U1347A- 27R-5, 12-14 cm; Fig. F1A), is an indication of rapid cooling. On the other hand, some samples only show very small grains that seem to be fresher (e.g., Sample 324-U1347A-28R-1, 5-7 $\mathrm{cm}$; Fig. F1B). In one of the samples, patterns that resemble oxy-exsolution patterns were observed (Sample 324-U1347A-27R-6, 6-8 cm; Fig. F1C). However, these patterns could also be caused by topography effects. Energy-dispersive X-ray measurements indicate a large variation in titanium content even within a sample. For instance, the Ti/Fe ratio for the grains analyzed in Sample 324-U1347A-28R-1, 5-7 $\mathrm{cm}$, range from 0 to 0.9 .

\section{Hole U1349A}

The five observed samples show little alteration, and no skeletal grains were observed in any of the samples (Fig. F1D-F1F). Iron oxide grains have sizes that range between a few micrometers and a few tens of micrometers. Again, within one sample, Ti/Fe ratios vary from 0 to 0.8 .

\section{Hole U1350A}

Seven samples were analyzed. In most of them, the iron oxide grains have a skeletal shape. (e.g., Sample 324-U1350A-25R-7, 5-7 cm; Fig. F1G). In the most extreme cases of alteration, the remaining iron oxide grains are very small $(\sim 1 \mu \mathrm{m})$ as a result of the larger grains breaking up (e.g., Sample 324-U1350A-26R-7, 35-37 cm; Fig. F1H). One sample seems to show patterns that are characteristic of oxy-exsolution (Sample 324-U1350A-24R-1, 111-113 cm; Fig. F1I).

\section{Hysteresis and first-order reversal curve diagram measurements}

The FWHM as well as coercive fields for which the FORC distribution is maximum are shown in Table T1 for all the measured samples, together with hysteresis parameters measured from classical hysteresis loops. Some results and representative FORC diagrams are given in Carvallo et al. (in press).

\section{Hole U1347A}

Most samples from Hole U1347A have a single-domain (most contours are closed; Fig. F2A, F2B, F2E) to pseudosingle-domain (PSD; some contours intersect the $H_{\mathrm{c}}=0$ axis) (Fig. F2C, F2D, F2F, F2G) behavior, with moderate magnetostatic interactions. Only one coercivity peak is observed on all the FORC diagrams. The squareness ratios range between 0.096 and 0.324 , with seven out of nine values $<0.2$. Bulk coercivity fields range between 3.25 and $8.37 \mathrm{mT}$, and the sample with the highest $M_{\mathrm{r}} / M_{\mathrm{s}}$ ratio has a bulk coercivity field $>13 \mathrm{mT}$. The $H_{\mathrm{cr}} / H_{\mathrm{c}}$ ratios are between 1.40 and 5.13, with eight values out of nine $<3 \mathrm{mT}$. The FWHM values are between 5 and $15 \mathrm{mT}$, which indicates small to moderate magnetostatic interactions. Finally, it is interesting to note that the variations of coercivity values that correspond to the maximum of the FORC distribution are consistent with the variations of bulk coercivities obtained from hysteresis loops, but are consistently lower.

\section{Hole U1349A}

For the samples from Hole U1349A, one sample per lava flow was measured. Sample 324-U1350A-12R-1, 87-89 cm, has clear PSD-like characteristics (Fig. F3C), but the other three are single-domain-like, with most contours that are closed (Fig. F3A, F3B, F3D). This is in agreement with hysteresis parameters: $M_{\mathrm{r}} / M_{\mathrm{s}}$ ratios are between 0.26 and 0.42 for these five samples and bulk coercivities are between 15 and $25 \mathrm{mT} . H_{\mathrm{cr}} / H_{\mathrm{c}}$ ratios are $<2$ for the single-domain-like samples and $<4$ for the PSD-like sample. Magnetostatic interactions are moderate, as suggested by the FWHM values, which are $<20 \mathrm{mT}$ in four out of five samples.

\section{Hole U1350A}

All 12 samples measured from Hole U1350A are very similar (Fig. F4). FORC diagrams are single-domainlike, with only two or three contours that do not close. $M_{\mathrm{r}} / M_{\mathrm{s}}$ ratios all range between 0.173 and 0.276 , and bulk coercivities range between 6 and 13 
mT, with 13 values out of $14<10 \mathrm{mT}$. The $H_{\mathrm{cr}} / H_{\mathrm{c}}$ ratios range between 1.53 and 2.17. The FWHM values are all $<10 \mathrm{mT}$, which shows that interactions are low. The variability of these parameters is much lower than that found in Holes U1347A and U1349A.

When plotted on a Day diagram, the hysteresis parameters of most of the samples fall on the single-domain-multidomain mixing line of Dunlop (2002), with a higher concentration of $>50 \%$ single-domain grains (Fig. F5).

\section{Susceptibility versus temperature}

\section{Hole U1347A}

The three measured samples from Hole U1347A all show different behaviors, but they have in common that the Curie temperatures upon heating are all quite similar and between $160^{\circ}$ and $200^{\circ} \mathrm{C}$. These are values that are typical of titanomagnetite $\mathrm{Fe}_{3-x} \mathrm{Ti}_{x} \mathrm{O}_{4}$ with $x=0.6$. However, the degrees of reversibility of these three samples are all different. In the three samples, susceptibility increases strongly from low temperature to the Curie temperature and then decreases very sharply. Sample 324-U1347A-28R-1, 5-7 $\mathrm{cm}$ (Fig. F6A), is almost perfectly reversible. This indicates the presence of homogeneous Ti-rich titanomagnetites (Kontny et al., 2003; Camps et al., 2011). According to these previous studies, this type of curve also corresponds to samples that are predominantly multidomain at room temperature, but the FORC measurements for these samples are rather characteristic of PSD grain size. Sample 324-U1347A27R-5, 12-14 cm (Fig. F6B), seems to transform to titanomagnetite with a higher Curie temperature (i.e., lower titanium content) when heated. Finally, Sample 324-U1347A-27R-2, 89-91 cm (Fig. F6C), shows a complex mineralogy: two components are visible upon cooling after heating to $450^{\circ} \mathrm{C}$ and the susceptibility is strongly irreversible after subsequent heating to $550^{\circ} \mathrm{C}$.

\section{Hole U1349A}

Four samples from Hole U1349A were measured. Two different types can be identified in the $k-T$ curves. The first type, in the samples from the uppermost part of the flow, is characterized by a fairly reversible susceptibility with heating and a high Curie temperature, close to that of pure magnetite (Fig. F6D, F6F, F6G). Similar curves were measured by Kontny et al. (2003) and Camps et al. (2011); the presence of magnetite can be interpreted as resulting from high-temperature oxidation. The second type, in the lowermost part of the flow, shows the presence of two Curie temperatures (Fig. F6E): one around $380^{\circ} \mathrm{C}$ and more or less pronounced, indicative of Ti-rich titanomagnetite(-maghemite), and one around $550^{\circ} \mathrm{C}$, indicative of Ti-poor titanomagnetite. Upon cooling, only the highest Curie temperature remains and the component with the lowest Curie temperature completely disappears. This behavior could be caused by the inversion of small grains of the low-temperature titanomaghemite phase into hematite.

\section{Hole U1350A}

Ten samples from Hole U1350A were measured. Because of their complex behavior, two or three partial $k$ - $T$ curves were also measured for some samples: the heating phase was stopped at an intermediate temperature, the sample was cooled down, and the susceptibility was measured again to a higher temperature and cooled down again. The $k-T$ curves display a range of different behaviors, but the main features are similar to Type $1 \mathrm{a} / 2$ from Kontny et al. (2003): two Curie temperatures are present upon heating, indicating the presence of two magnetic phases. After heating, only one Curie temperature remains. The curves are quite reversible upon heating to $\sim 300^{\circ} \mathrm{C}$, indicating that the mineralogical changes take place mainly after that temperature. The three Curie temperatures can all be very close (Fig. F6N, F6O, for instance), and the irreversibility can be more or less marked. Samples 324-U1350A-25R-2, 64-66 cm, and 26R-7, 35-37 cm (Fig. F6I, F6Q), have a particularly irreversible behavior, with a Curie temperature upon cooling much lower (by $\sim 100^{\circ} \mathrm{C}$ ) than the lowest $\mathrm{Cu}$ rie temperature of the starting material, as well as a lower bulk susceptibility.

\section{Low-temperature measurements}

\section{Hole U1347A}

Three samples from Hole U1347A were measured and show two different behaviors. The first behavior is observed in two flows from Hole U1347A, in Samples 324-U1347A-26R-2, 89-91 cm, and 27R-5,12-14 $\mathrm{cm}$ (Fig. F7A, F7B). The room-temperature SIRM stays constant until cooled to $150 \mathrm{~K}$ and then decreases through a broad transition to $60 \%$ of its original value. The low-temperature SIRM increases with heating to $120 \mathrm{~K}$ and then decreases almost linearly to room temperature, reaching half its original value. This behavior could indicate the presence of a very broad Verwey transition indicative of low-Ti content titanomagnetite. Sample 324-U1347A-28R-1, 74-76 $\mathrm{cm}$, is characterized by a different behavior (Fig. F7C): although the room-temperature SIRM varies very little with cooling, the shape of the SIRM demagnetization curve is very similar to that of syn- 
thetic titanomagnetite of composition $x=0.6$ (Moskowitz et al., 1998).

\section{Hole U1349A}

Samples from Hole U1349A also have two different behaviors. The first behavior was observed for two samples (Fig. F7D, F7E): (1) the room-temperature SIRM cooling curve shows a very small Verwey transition, more or less broad depending on the sample, which decreases the magnetization by no more than $10 \%$, and (2) the low-temperature SIRM decreases sharply at low temperature and then almost linearly, down to about two-thirds of the SIRM at $10 \mathrm{~K}$. This could indicate the presence of a superparamagnetic fraction whose magnetization is blocked at low temperature and unblocks with heating. A slightly different behavior is observed in the other five measured samples (e.g., Sample 324-U1349A-10R-1, 116-118 $\mathrm{cm}$ Fig. F7G): the room-temperature SIRM is almost constant with cooling and no transition is observed, whereas the low-temperature SIRM decreases almost exponentially to about half its original value, showing again the presence of superparamagnetic grains.

\section{Hole U1350A}

All the samples from Hole U1350A have a similar behavior (Fig. F7K, F7N): the room-temperature SIRM decreases by two-thirds through a broad transition centered around $120 \mathrm{~K}$. The low-temperature SIRM decreases through a small transition at $45 \mathrm{~K}$ and then drops almost linearly between 100 and $300 \mathrm{~K}$ to reach a value about half the original low-temperature SIRM.

\section{Acknowledgments}

We thank IODP for receipt of samples. We also wish to thank Catherine Kissel and Carlo Laj for access to the AGM at the LSCE, Gif-sur-Yvette, and France Lagroix for access and help using the MPMS Magnetometer at IPGP, Paris.

\section{References}

Camps, P., Singer, B.S., Carvallo, C., Goguitchaichvili, A., Fanjat, G., and Allen, B., 2011. The Kamikatsura event and the Matuyama-Brunhes reversal recorded in lavas from Tjörnes Peninsula, northern Iceland. Earth Planet. Sci. Lett., 310(1-2):33-44. doi:10.1016/ j.epsl.2011.07.026
Carvallo, C., Camps, P., Ooga, M., Fanjat, G., and Sager, W.W., in press. Palaeointensity determinations and rock magnetic properties on basalts from Shatsky Rise: new evidence for a Mesozoic dipole low. Geophys. J. Int. doi:10.1093/gji/ggs100

Dunlop, D.J., 2002. Theory and application of the Day plot $\left(M_{\mathrm{rs}} / M_{\mathrm{s}}\right.$ versus $\left.H_{\mathrm{cr}} / H_{\mathrm{c}}\right), 1$. Theoretical curves and tests using titanomagnetite data. J. Geophys. Res., [Solid Earth], 107(B3):2056. doi:10.1029/2001JB000486

Expedition 324 Scientists, 2010a. Expedition 324 summary. In Sager, W.W., Sano, T., Geldmacher, J., and the Expedition 324 Scientists, Proc. IODP, 324: Tokyo (Integrated Ocean Drilling Program Management International, Inc.). doi:10.2204/iodp.proc.324.101.2010

Expedition 324 Scientists, 2010b. Site U1347. In Sager, W.W., Sano, T., Geldmacher, J., and the Expedition 324 Scientists, Proc. IODP, 324: Tokyo (Integrated Ocean Drilling Program Management International, Inc.). doi:10.2204/iodp.proc.324.104.2010

Expedition 324 Scientists, 2010c. Site U1350. In Sager, W.W., Sano, T., Geldmacher, J., and the Expedition 324 Scientists, Proc. IODP, 324: Tokyo (Integrated Ocean Drilling Program Management International, Inc.). doi:10.2204/iodp.proc.324.107.2010

Kontny, A., Vahle, C., and de Wall, H., 2003. Characteristic magnetic behavior of subaerial and submarine lava units from the Hawaiian Scientific Drilling Project (HSDP-2). Geochem., Geophys., Geosyst., 4(2):8703. doi:10.1029/2002GC000304

Moskowitz, B.M., Jackson, M., and Kissel, C., 1998. Lowtemperature magnetic behavior of titanomagnetites. Earth Planet. Sci. Lett., 157(3-4):141-149. doi:10.1016/ S0012-821X(98)00033-8

Pike, R.P., Roberts, A.P., and Verosub, K.L., 1999. Characterizing interactions in fine magnetic particle systems using first order reversal curves. J. Appl. Phys., 85(9):6660-6667. doi:10.1063/1.370176

Roberts, A.P., Pike, C.R., and Verosub, K.L., 2000. Firstorder reversal curve diagrams: a new tool for characterizing the magnetic properties of natural samples. J. Geophys. Res., [Solid Earth], 105(B12):28461-28475. doi:10.1029/2000JB900326

Sager, W.W., 2005. What built Shatsky Rise, a mantle plume or ridge tectonics? In Foulger, G.R., Natland, J.H., Presnall, D.C., and Anderson, D.L. (Eds.), Plates, Plumes, and Paradigms. Spec. Pap.-Geol. Soc. Am., 388:721733. doi:10.1130/0-8137-2388-4.721

Initial receipt: 29 March 2012

Acceptance: 20 November 2012

Publication: 27 February 2013

MS 324-201 

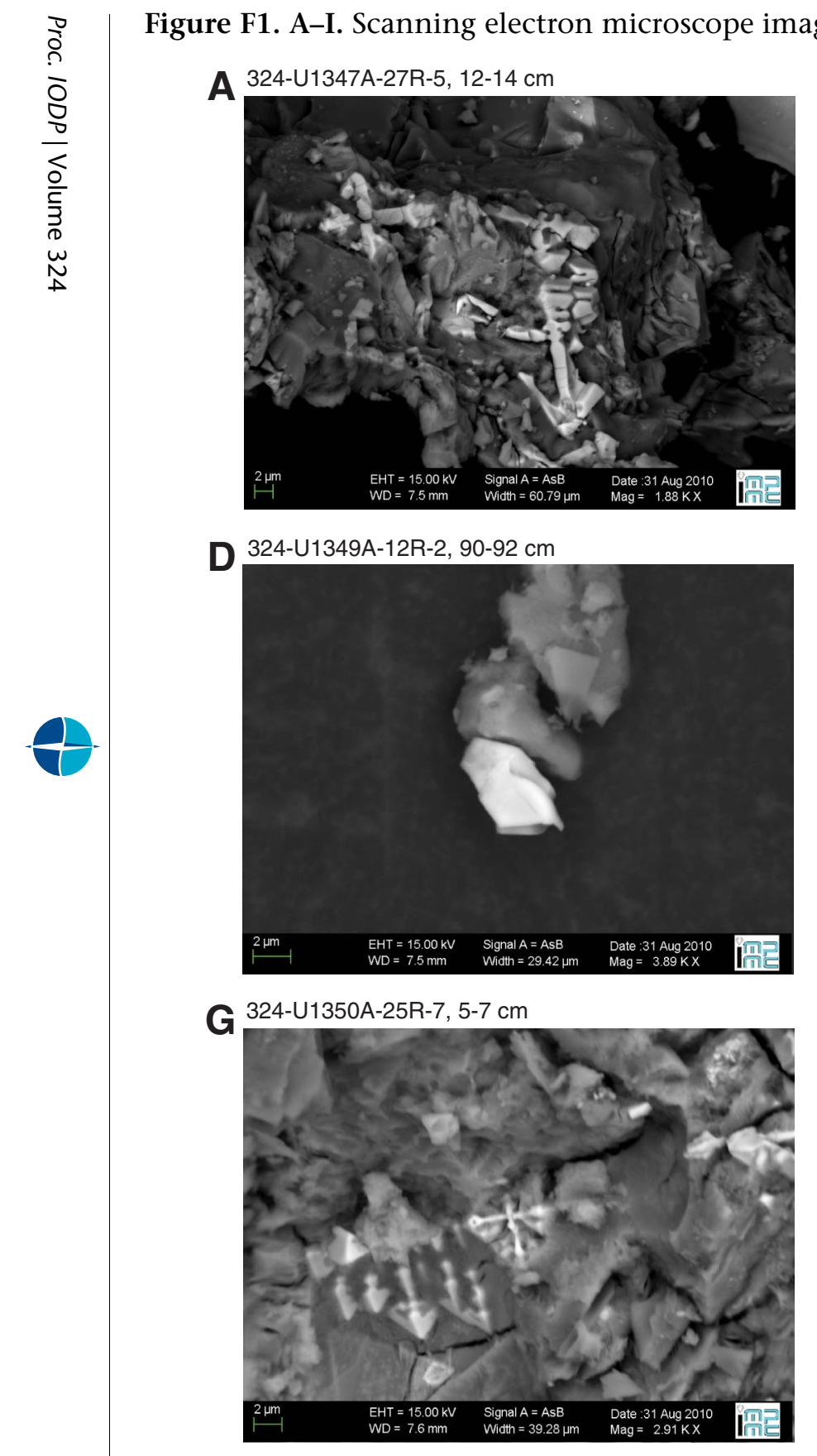

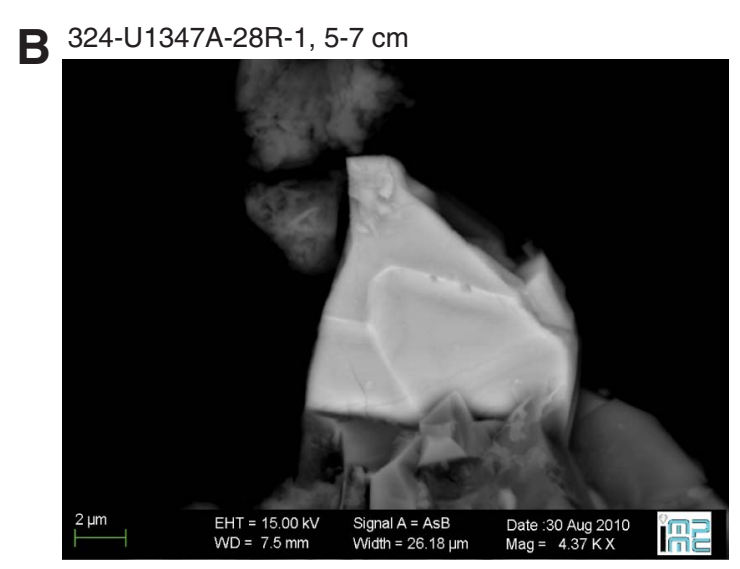

E 324-U1349A-9R-3, 50-52 cm

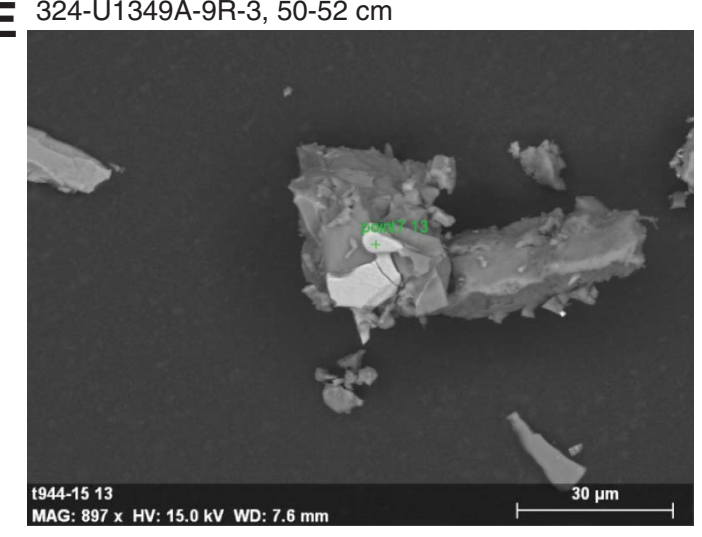

H 324-U1350A-26R-7, 35-37 cm

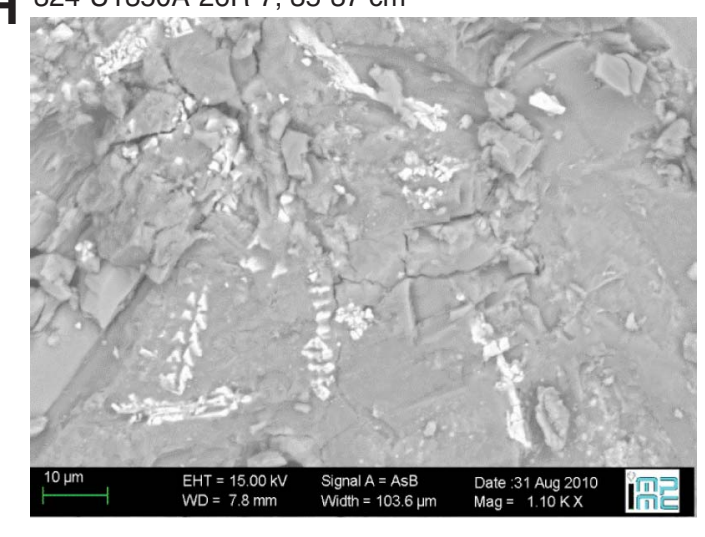

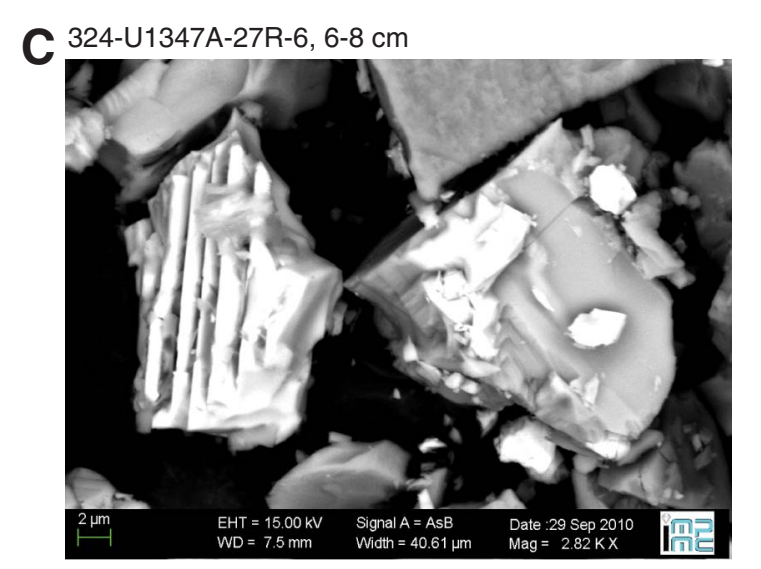

F $324-U 1349 A-12 R-2,90-92 \mathrm{~cm}$

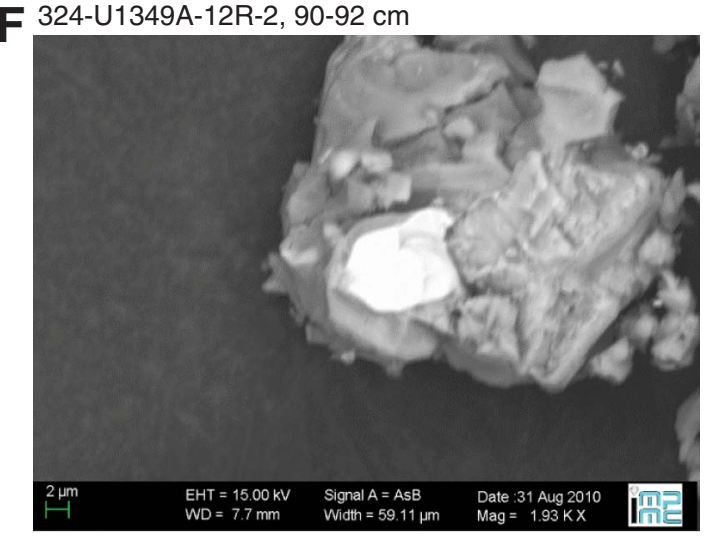

I24-U1350A-24R-1, 111-113 cm

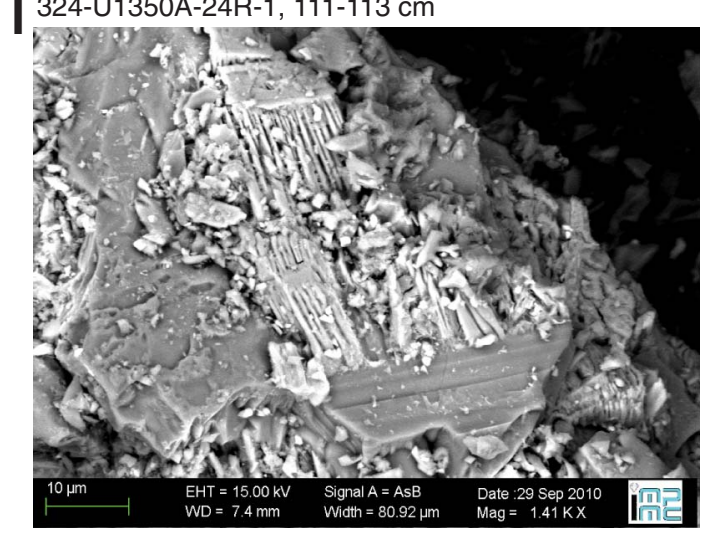


Figure F2. A-H. First-order reversal curve diagrams for samples from Hole U1347A.
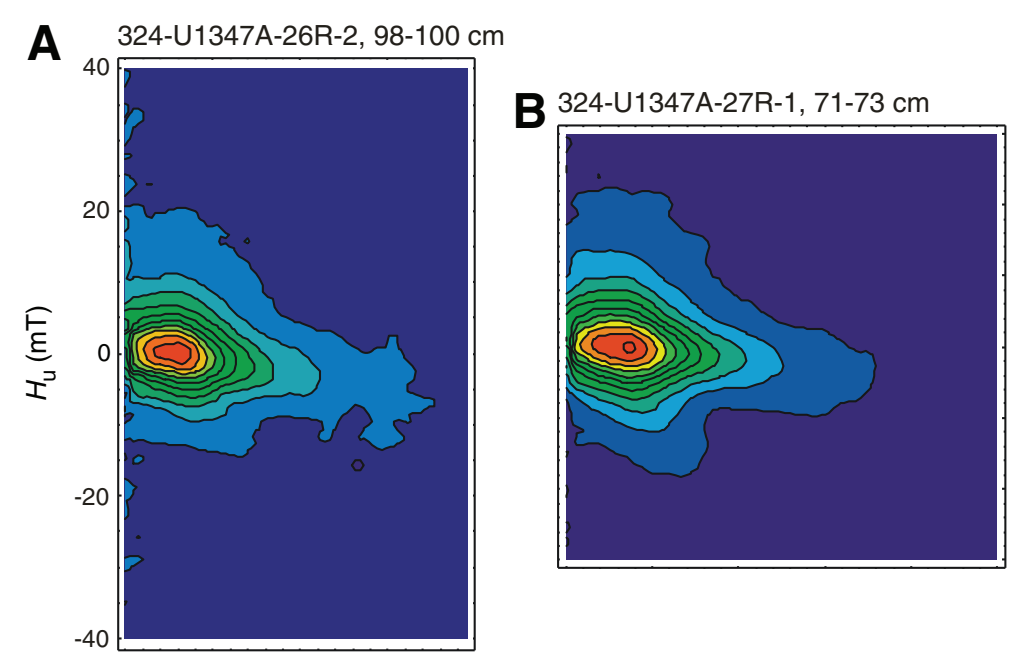

C 324-U1347A-27R-3, 4-6 cm
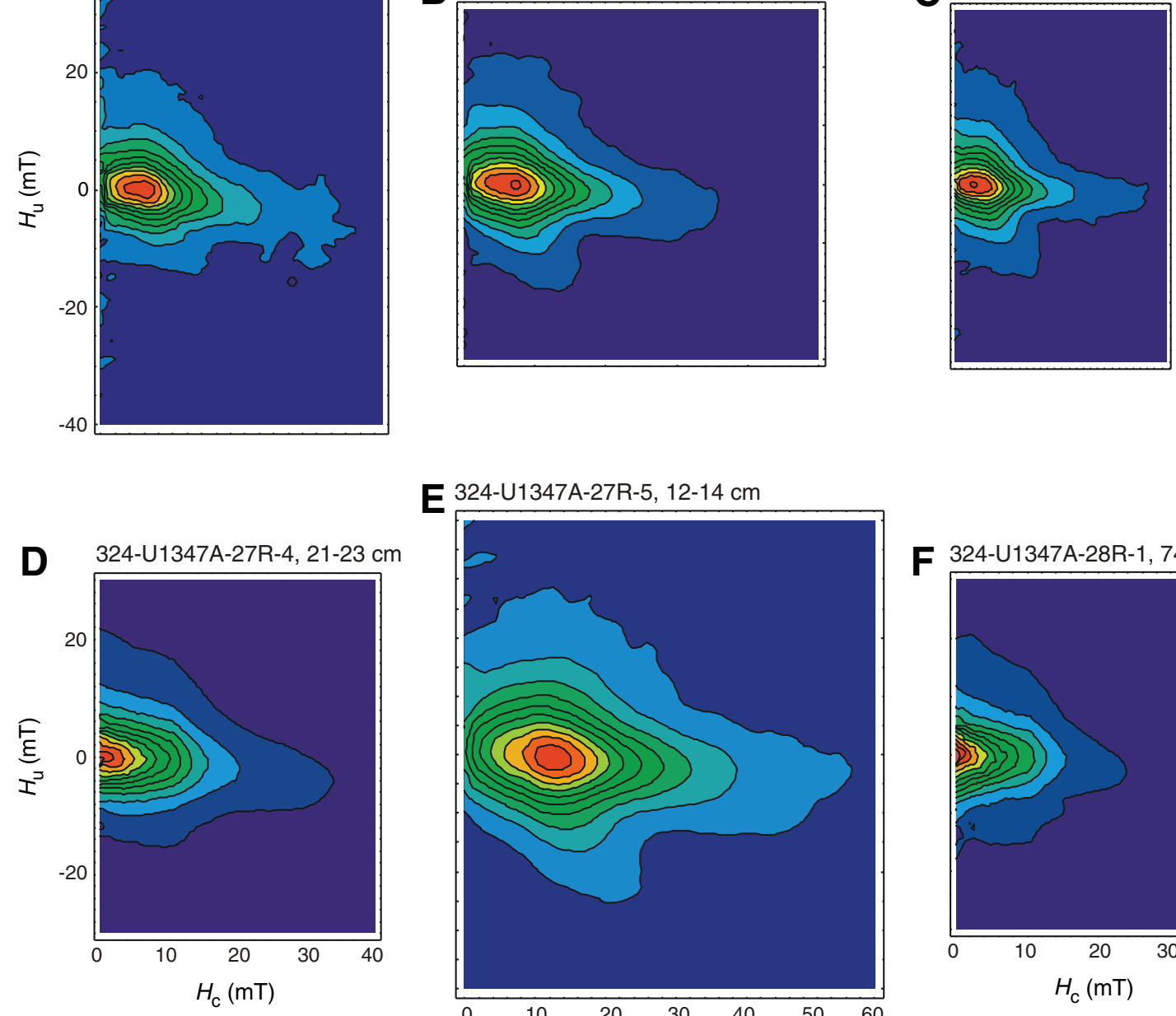

E $324-U 1347 A-27 R-5,12-14 \mathrm{~cm}$
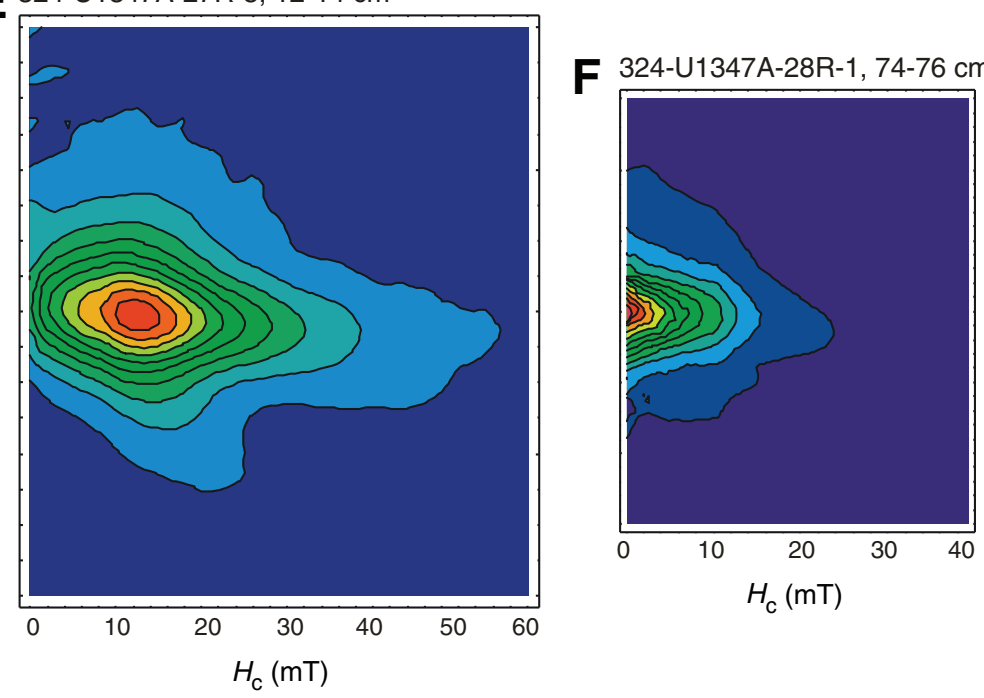

$\mathbf{G}^{324-U 1347 A-27 R-6,119-121 \mathrm{~cm}}$

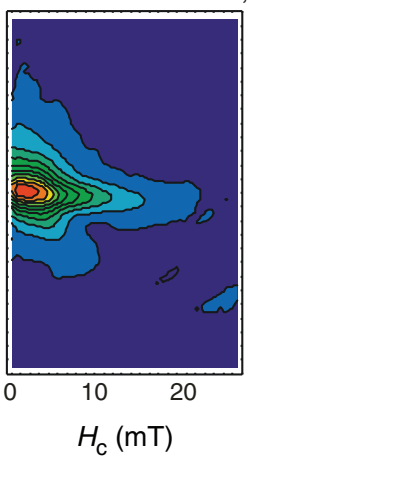


Figure F3. A-D. First-order reversal curve diagrams for samples from Hole U1349A.
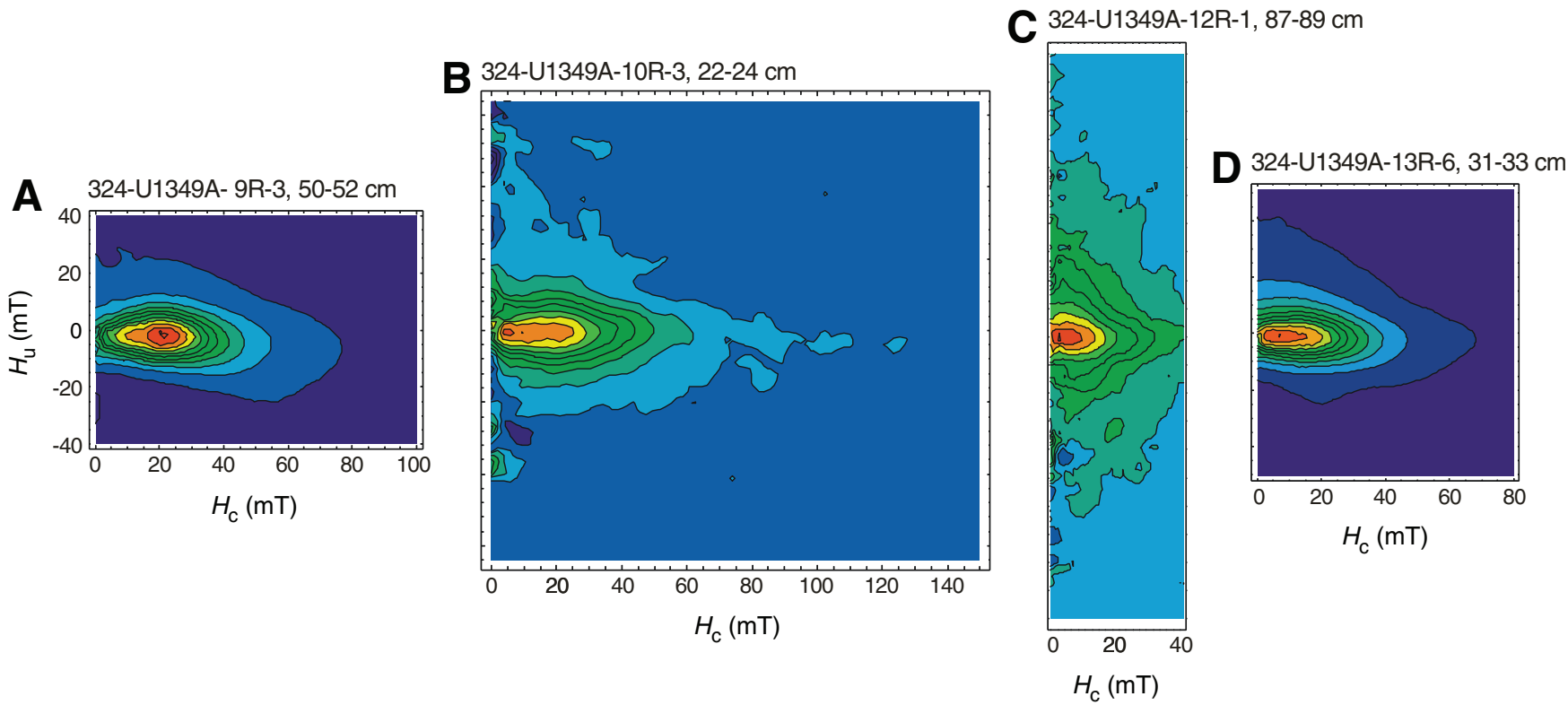
Figure F4. A-L. First-order reversal curve diagrams for samples from Hole U1350A.
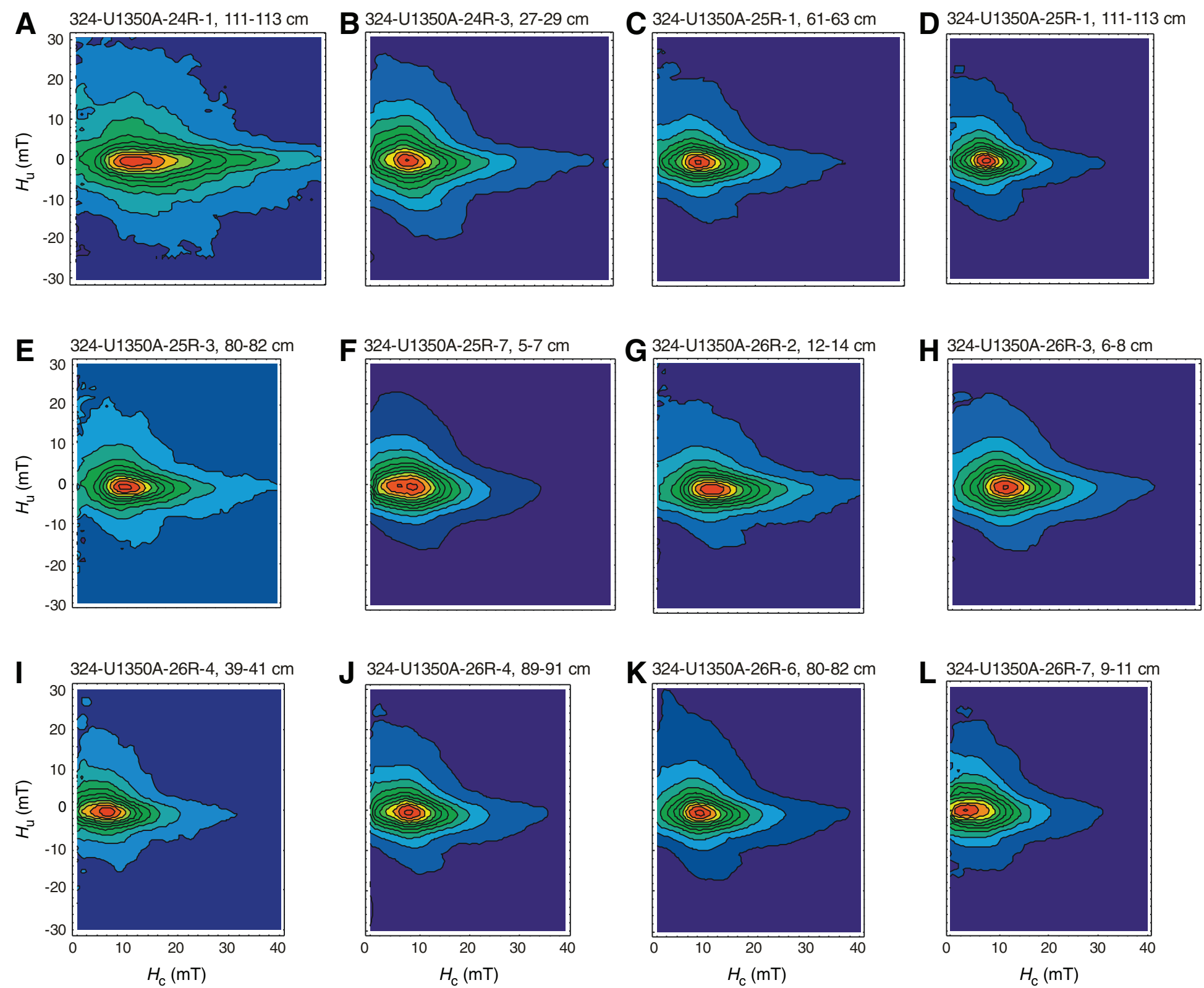
Figure F5. Day plots for the samples measured for first-order reversal curve diagrams and hysteresis parameters, Expedition 324. Solid line is the single-domain (SD)-multidomain (MD) mixing line of Dunlop et al. (2002). Crosses $=$ Hole U1347A samples, circled crosses $=$ Hole U1349A samples, diamonds $=$ Hole U1350A samples . Solid circles $=$ SD-MD points from Dunlop et al. (2002).

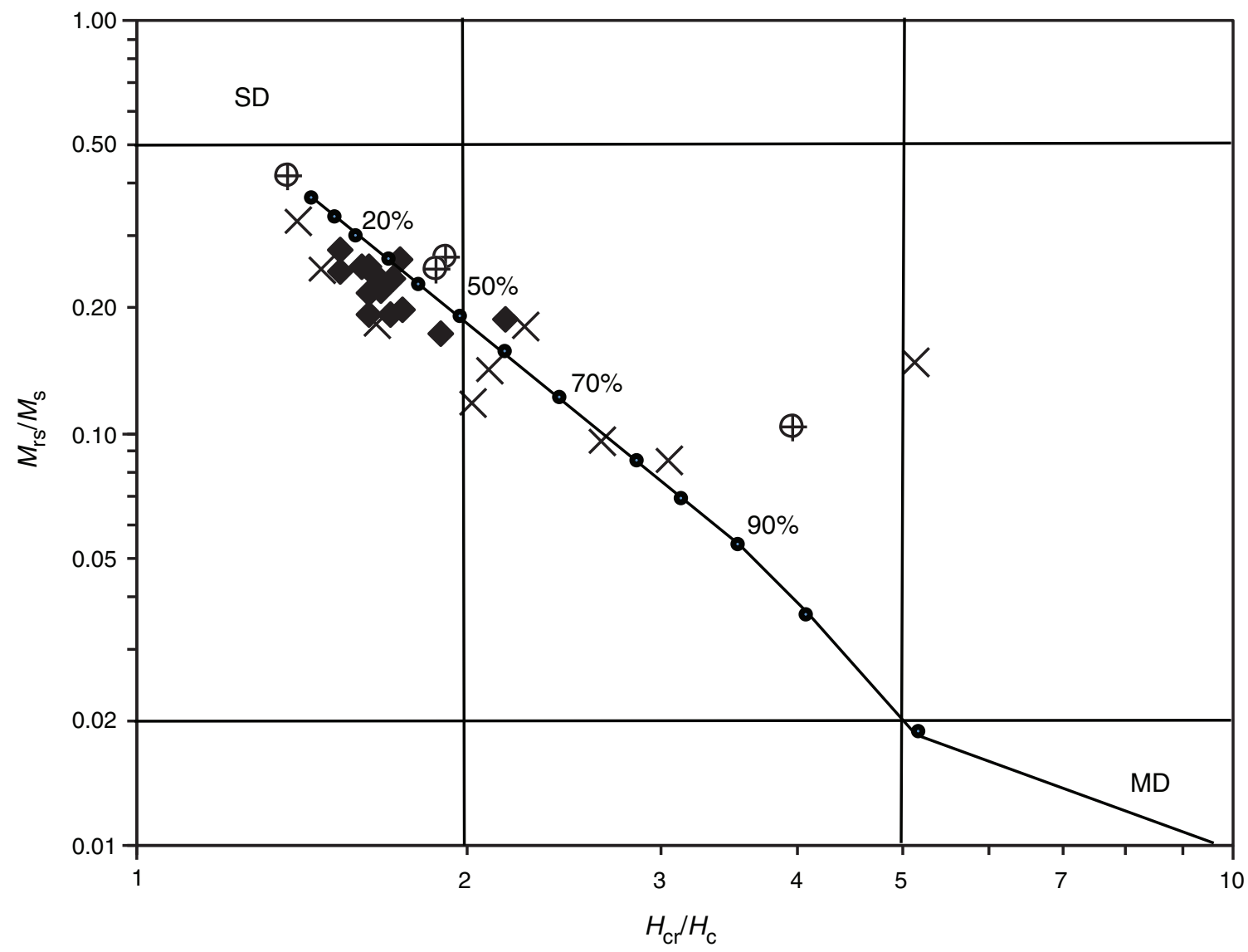


Figure F6. A-Q. Plots of low-field susceptibility vs. temperature curves. Heating and cooling curves are indicated with arrows. The curves labeled "1" are before heating-cooling cycle, and the curves labeled " 2 " are after heating-cooling cycle. (Continued on next page.)

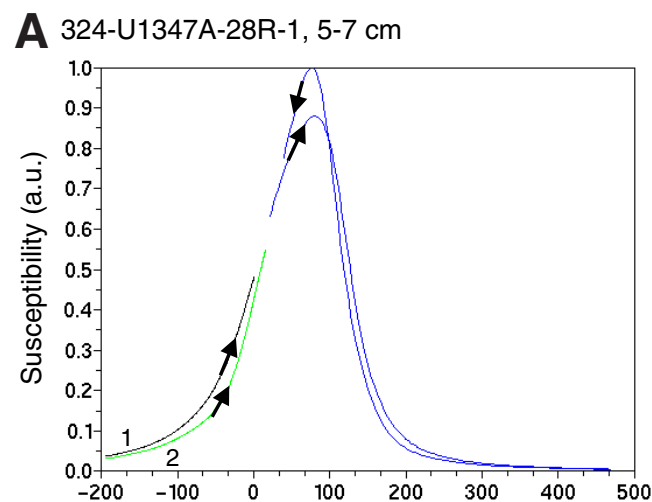

B 324-U1347A-27R-5, 12-14 cm

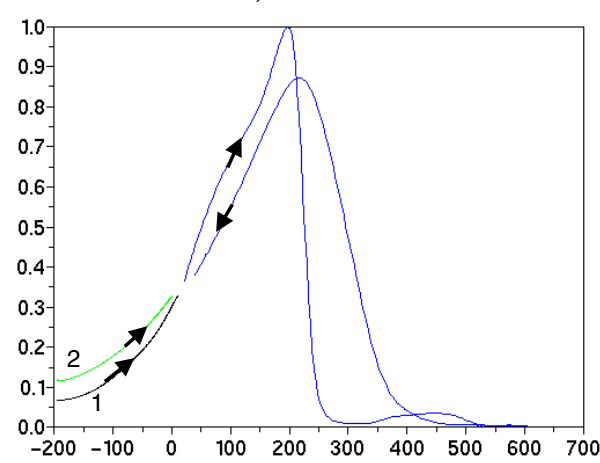

D 324-U1349A-9R-3, 50-52 cm

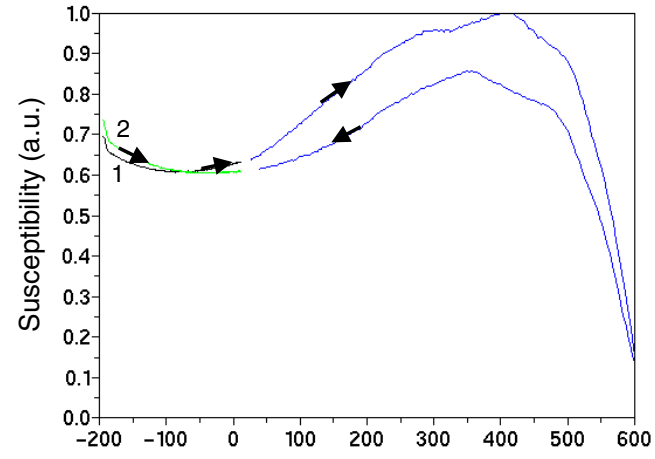

G 324-U1349A-12R-2, 90-92 cm

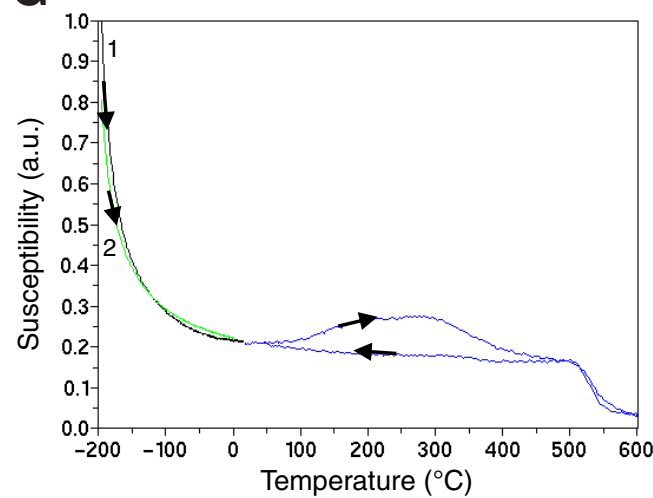

E $324-U 1349 \mathrm{~A}-12 \mathrm{R}-1,87-89 \mathrm{~cm}$

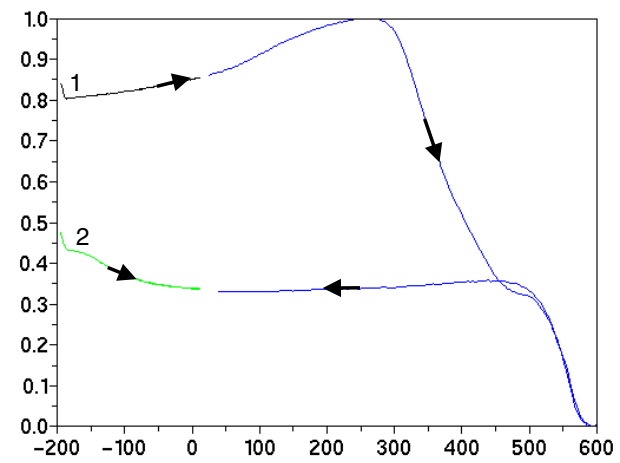

H 324-U1350A-24R-1, 111-113 cm

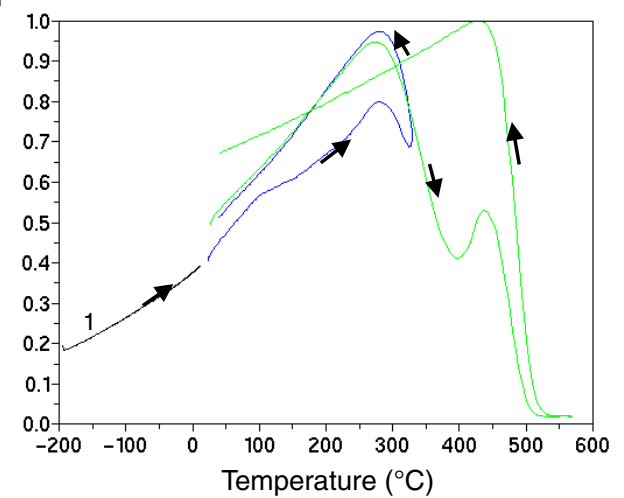

C 324-U1347A-26R-2, 89-90 cm

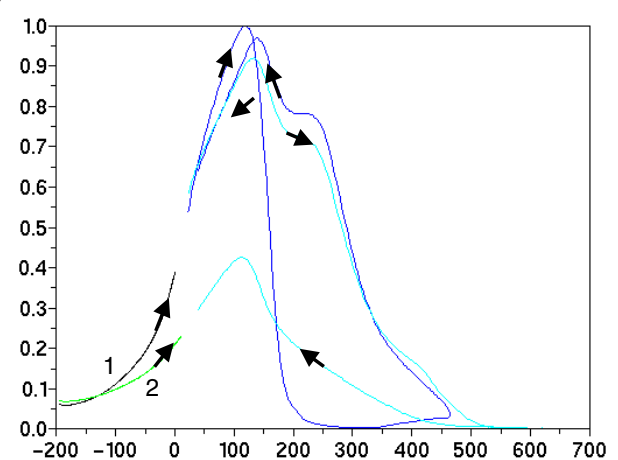

F 324-U1349A-10R-3, 110-112 cm

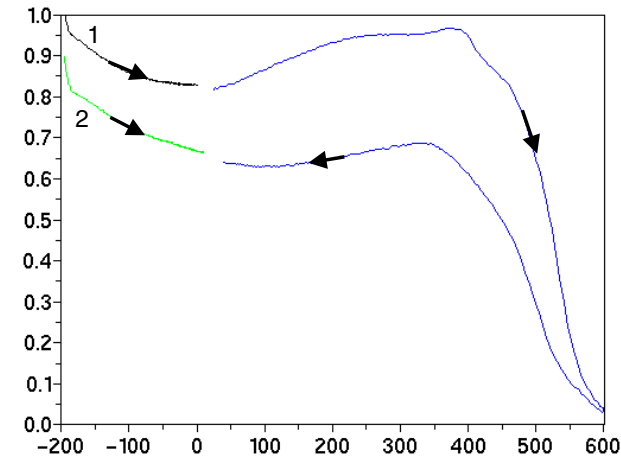

324-U1350A-25R-2, 64-66 cm

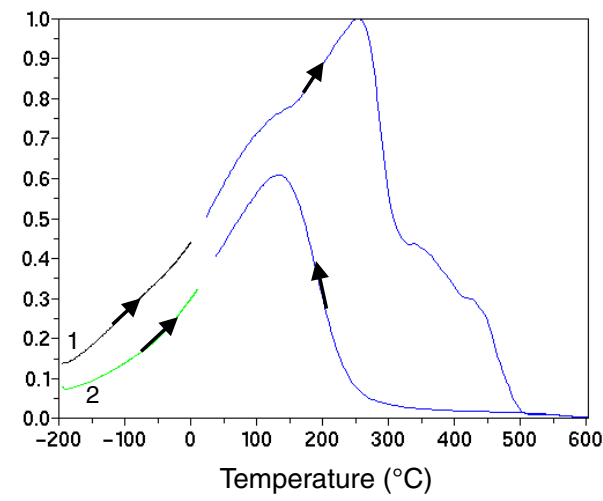



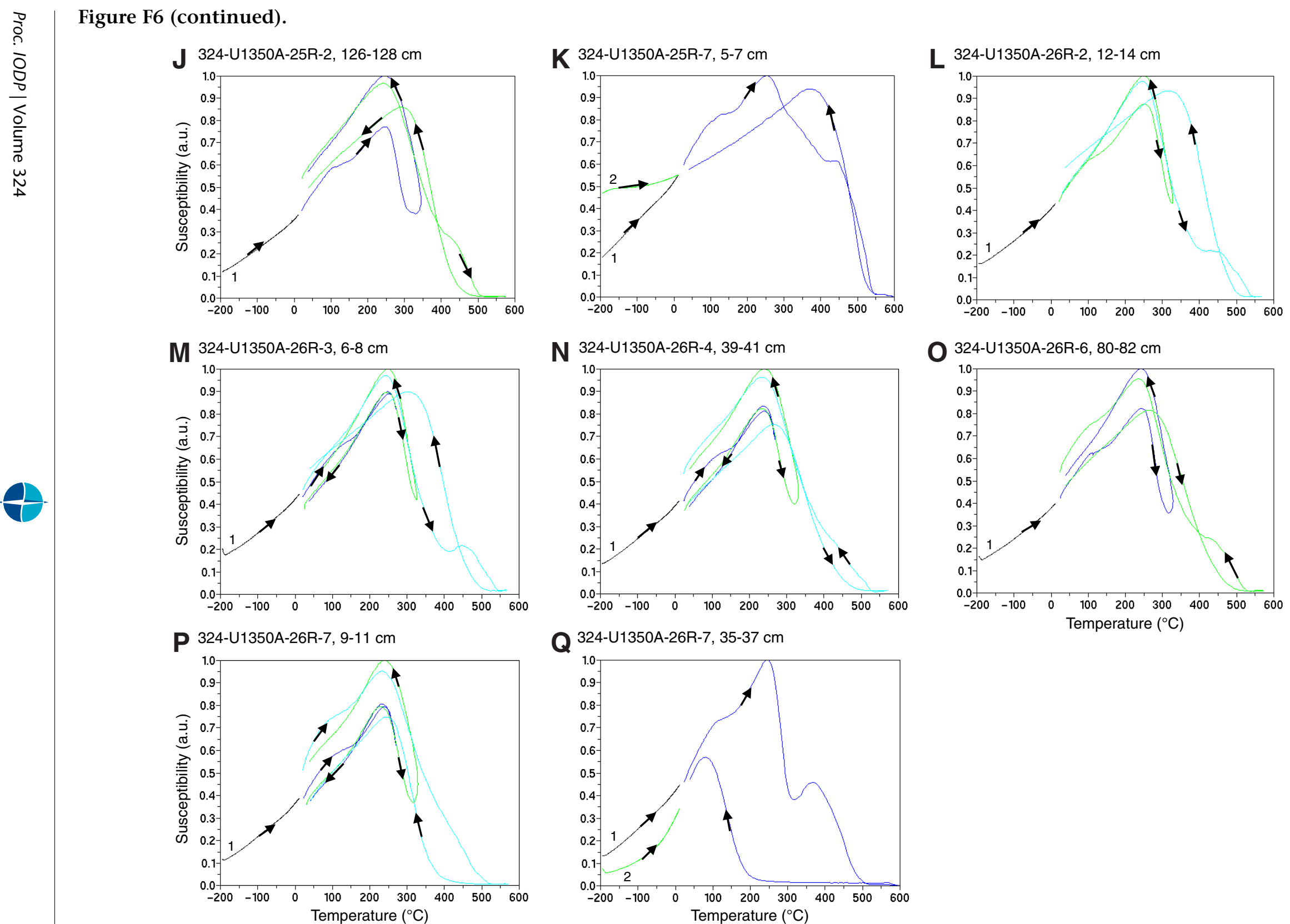

$\mathbf{Q}^{324-U 1350 A-26 R-7,35-37 \mathrm{~cm}}$

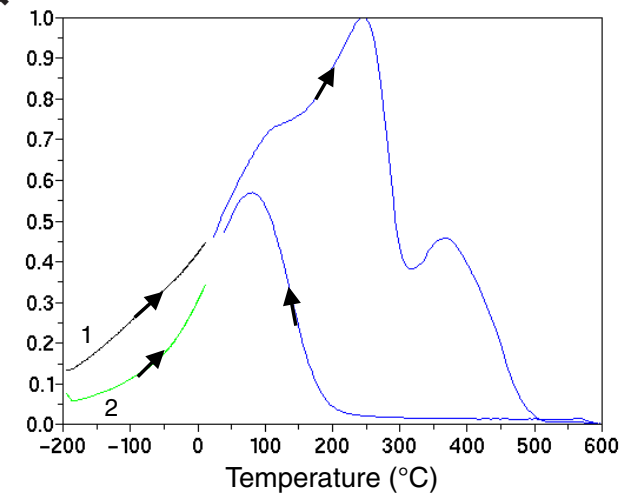


Figure F7. A-N. Plots of temperature dependence of saturation remanence (SIRM) produced by a 2.5 T field. The curves labeled " 1 " show the zerofield warming curve from 20 to $300 \mathrm{~K}$, and the curves labeled " 2 " show the zero-field cooling (from 300 to $20 \mathrm{~K}$ ) curve for SIRM produced at 300 K. (Continued on next page.)
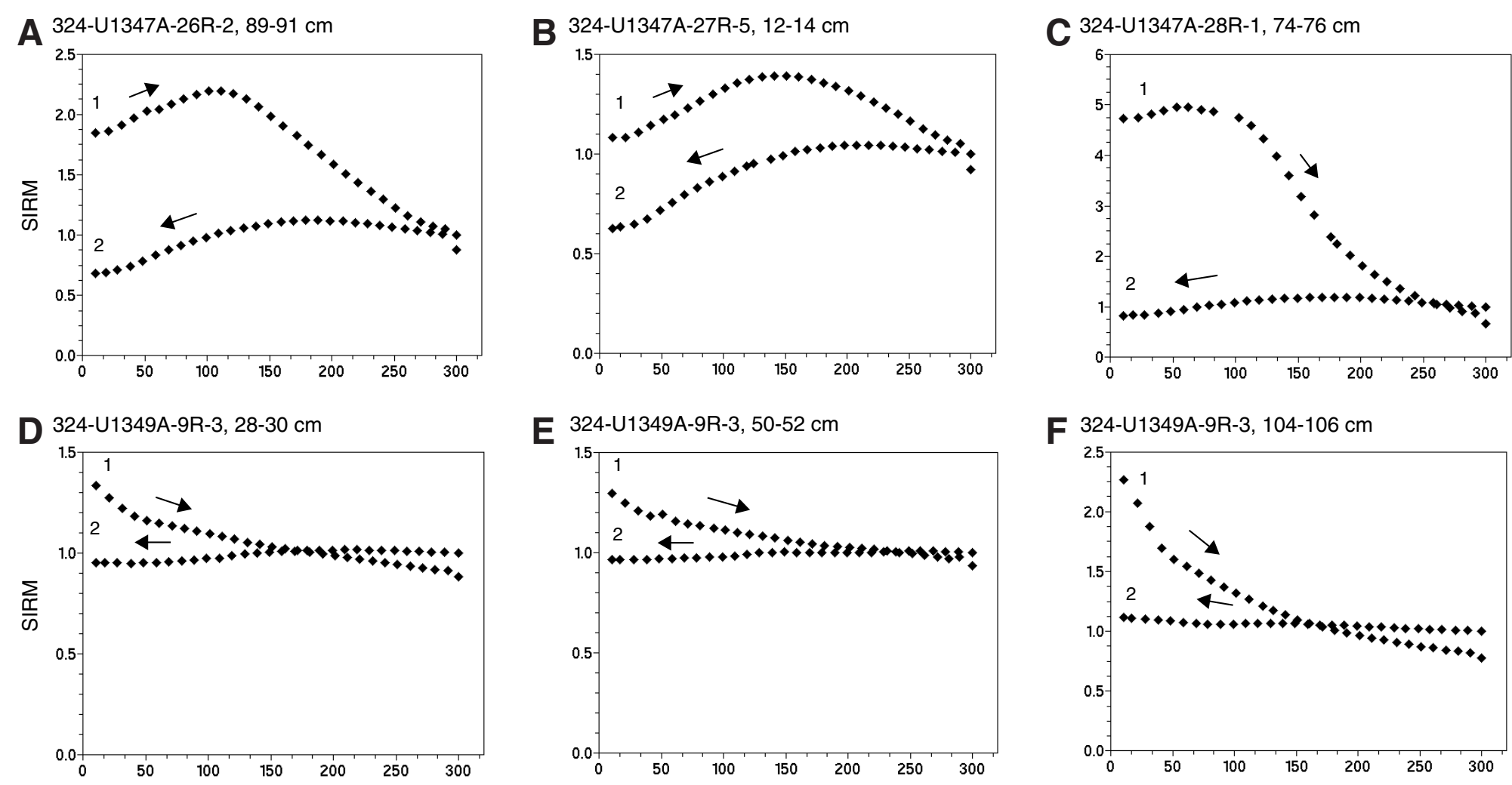

G 324-U1349A-10R-1, 116-118 cm

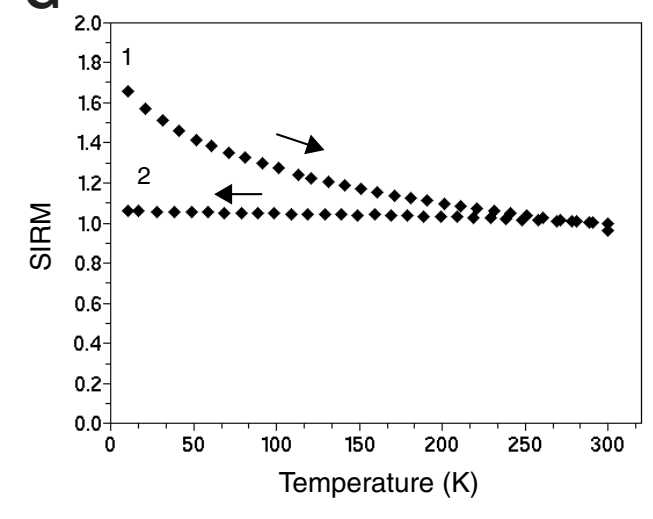

H 324-U1349A-10R-3, 22-24 cm

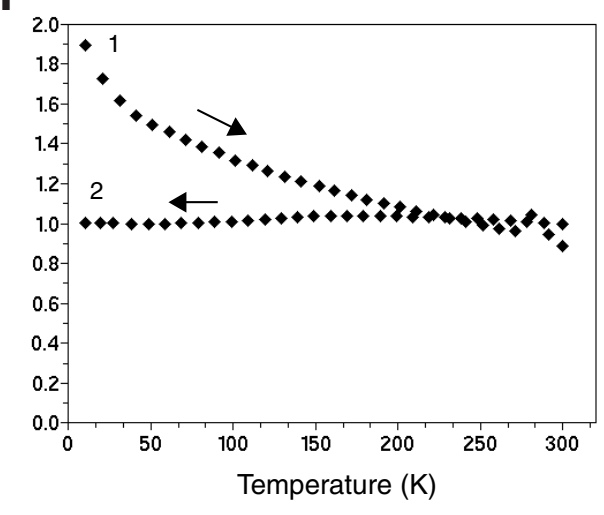

I 324-U1349A-12R-1, 87-89 cm

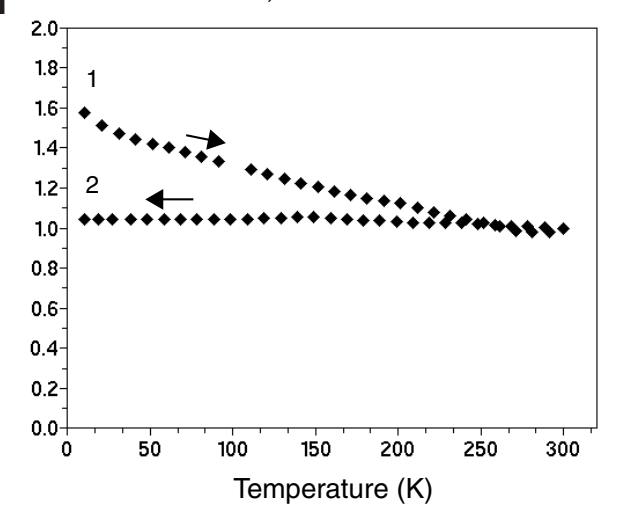



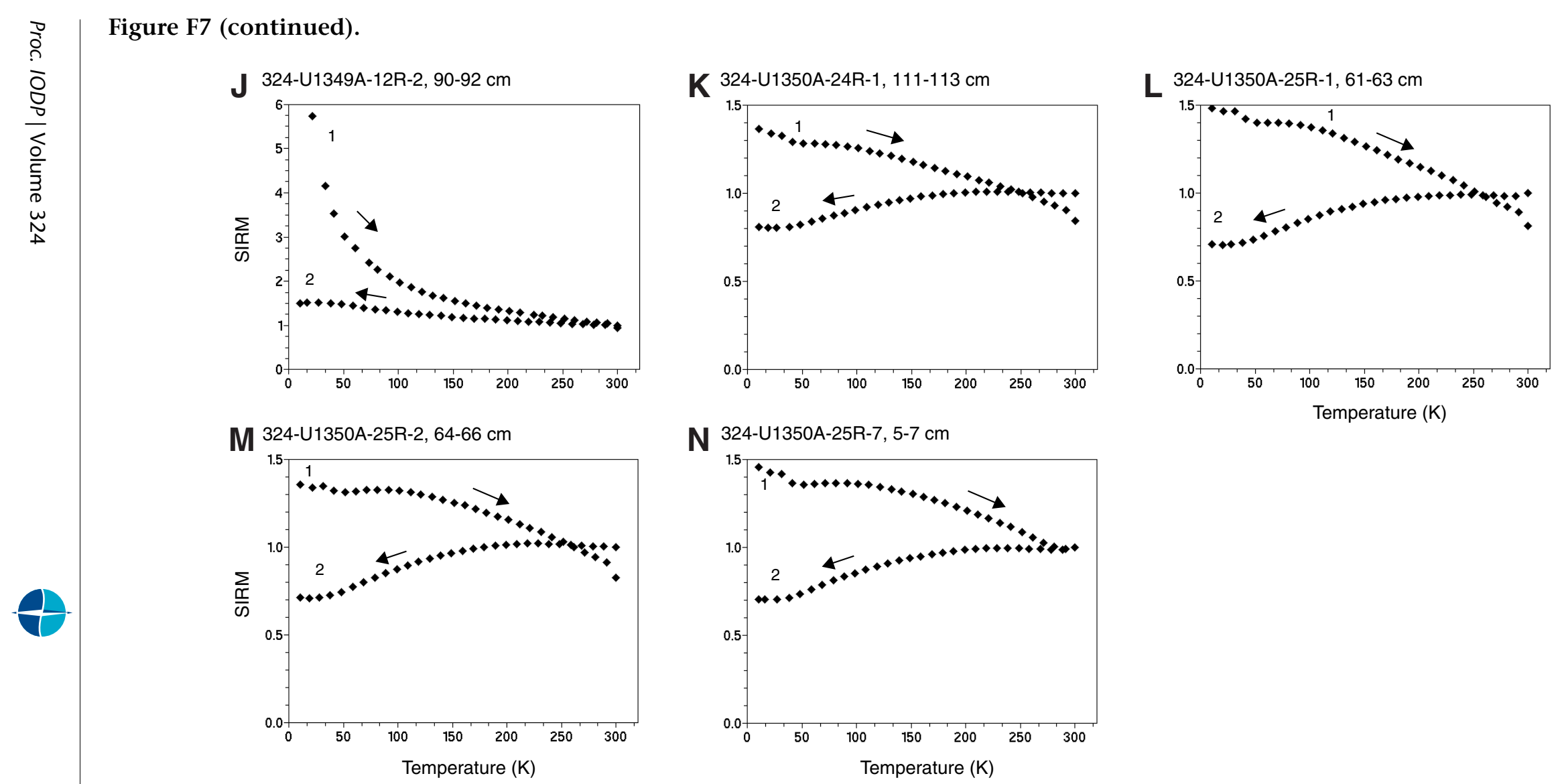
Table T1. Hysteresis parameters used for first-order reversal curve diagram measurements, Expedition 324.

\begin{tabular}{llrrrrr}
\hline $\begin{array}{l}\text { Core, section, } \\
\text { interval }(\mathrm{cm})\end{array}$ & $M_{\mathrm{r}} / M_{\mathrm{s}}$ & $\begin{array}{c}H_{\mathrm{c}} \\
(\mathrm{mT})\end{array}$ & $\begin{array}{c}H_{\mathrm{cr}} \\
(\mathrm{mT})\end{array}$ & $\begin{array}{r}H_{\mathrm{cr}} / H_{\mathrm{c}} \\
(\mathrm{mT})\end{array}$ & $\begin{array}{r}H_{\mathrm{c}} \text { FORC } \\
(\mathrm{mT})\end{array}$ \\
\hline 324-U1347A- & & & & & & \\
26R-2, 121-123 & 0.183 & 6.22 & 10.26 & 1.65 & 8.98 & 6.00 \\
27R-1, 71-73 & 0.248 & 8.37 & 12.30 & 1.47 & 10.35 & 4.90 \\
27R-3, 4-6 & 0.143 & 4.70 & 9.82 & 2.09 & 8.52 & 3.10 \\
27R-4, 21-23 & 0.180 & 6.57 & 14.85 & 2.26 & 9.06 & 0.00 \\
27R-5, 12-14 & 0.327 & 13.58 & 19.00 & 1.40 & 14.76 & 11.53 \\
27R-5, 125-127 & 0.118 & 3.72 & 7.51 & 2.02 & 5.19 & 2.28 \\
27R-6, 6-8 & 0.149 & 5.46 & 28.01 & 5.13 & 6.27 & 0.00 \\
27R-6, 119-121 & 0.096 & 3.25 & 8.61 & 2.65 & 5.72 & 1.46 \\
28R-1, 74-76 & 0.086 & 3.47 & 10.58 & 3.05 & 8.84 & 0.00 \\
324-U1349A- & & & & & & \\
9R-3, 50-52 & 0.421 & 23.48 & 32.17 & 1.37 & 15.35 & 20.50 \\
10R-3, 22-24 & 0.267 & 19.82 & 37.86 & 1.91 & 11.91 & 4.44 \\
12R-1, 87-89 & 0.103 & 7.34 & 29.14 & 3.97 & 20.85 & 1.31 \\
12R-2, 90-92 & 0.271 & 25.24 & 18.17 & 0.72 & 34.07 & 10.90 \\
13R-6, 31-33 & 0.249 & 14.43 & 26.98 & 1.87 & 13.63 & 6.22 \\
324-U1350A- & & & & & & \\
24R-1, 111-113 & 0.263 & 12.56 & 21.85 & 1.74 & 8.38 & 11.71 \\
24R-3, 27-29 & 0.222 & 8.15 & 13.61 & 1.67 & 9.87 & 7.52 \\
25R-1, 61-63 & 0.218 & 7.56 & 12.32 & 1.63 & 7.38 & 7.84 \\
25R-1, 111-113 & 0.194 & 6.28 & 10.24 & 1.63 & 6.78 & 7.11 \\
25R-2, 64-66 & 0.253 & 9.21 & 15.01 & 1.63 & 7.28 & 9.05 \\
25R-3, 80-82 & 0.245 & 8.96 & 13.71 & 1.53 & 7.06 & 9.41 \\
25R-7, 5-7 & 0.235 & 7.83 & 13.39 & 1.71 & 9.72 & 7.78 \\
26R-2, 12-14 & 0.254 & 9.35 & 14.96 & 1.60 & 7.04 & 10.45 \\
26R-3, 6-8 & 0.276 & 9.44 & 14.44 & 1.53 & 8.89 & 9.89 \\
26R-4, 39-41 & 0.194 & 6.00 & 10.20 & 1.70 & 7.16 & 5.75 \\
26R-4, 89-91 & 0.173 & 6.83 & 12.91 & 1.89 & 7.71 & 7.70 \\
26R-6, 80-82 & 0.198 & 7.09 & 12.41 & 1.75 & 10.05 & 2.27 \\
26R-7, 9-11 & 0.189 & 6.00 & 13.00 & 2.17 & 8.00 & 3.24 \\
26R-7, 96-98 & 0.241 & 9.62 & 15.78 & 1.64 & 8.40 & 10.41 \\
\hline & & & & & & \\
\hline
\end{tabular}

$M_{\mathrm{r}} / M_{\mathrm{s}}=$ remanent magnetization/saturation magnetization, $H_{\mathrm{cr}}=$ remanent coercive field, $H_{\mathrm{c}}=$ coercive field, FWHM = full width at half maximum of the first-order reversal curve (FORC) distribution parallel to the $H_{\mathrm{u}}$ axis that goes through the distribution maximum, $H_{\mathrm{c}} \mathrm{FORC}=\mathrm{coercive}$ field for which the FORC distribution is maximum. 